\title{
Ophthalmic Artery Blood Flow Velocity in Healthy Term and Preterm Neonates ${ }^{1}$
}

\author{
WOLFGANG LINDNER, MICHAELA SCHAUMBERGER, AND HANS T. VERSMOLD \\ Department of Pediatrics [W.L., M.S.] and Division of Neonatology [H.T.V.], Department Gynecology and
}

Obstetrics, Klinikum Grosshadern, University of Munich, Federal Republic of Germany

\begin{abstract}
Ophthalmic artery blood flow velocity (OA$\mathrm{BFV}, \mathrm{cm} / \mathrm{s})$, cerebral blood flow velocity $(\mathrm{C}-\mathrm{BFV}, \mathrm{cm} / \mathrm{s})$, and cardiac output $(\mathrm{ml} / \mathrm{min})$ were measured by pulsed Doppler sonography in 15 healthy term and 10 well preterm (26-35 wk) infants in the first week of life. OA-BFV did not increase with increasing gestational age (preterm: peak systolic BFV $29 \pm 5 \mathrm{~cm} / \mathrm{s}$, mean BFV $7.2 \pm 1.5 \mathrm{~cm} /$ s; term: peak systolic BFV $27 \pm 5 \mathrm{~cm} / \mathrm{s}$, mean BFV $6.6 \pm$ $1.3 \mathrm{~cm} / \mathrm{s}$ ), unlike C-BFV (preterm: peak systolic BFV 34 $\pm 8 \mathrm{~cm} / \mathrm{s}$, mean BFV $9.4 \pm 2.3 \mathrm{~cm} / \mathrm{s}$; term: peak systolic BFV $43 \pm 9 \mathrm{~cm} / \mathrm{s}, p<0.05$; mean BFV $11 \pm 3.0 \mathrm{~cm} / \mathrm{s}, p$ $<0.05$ ) and cardiac output (preterm $329 \pm 128 \mathrm{ml} / \mathrm{min}$, term $732 \pm 112 \mathrm{ml} / \mathrm{min} ; p<0.001$ ). The ratio of $\mathrm{OA}-\mathrm{BFV} /$ C-BFV was significantly higher in preterm than in term infants $(p<0.01)$. In preterm infants, but not in term infants, there was a positive linear correlation of $\mathrm{OA}-\mathrm{BFV}$ to $\mathrm{C}$-BFV $(r=0.88)$. We conclude that it is possible to measure opthalmic artery blood flow velocity in neonates by pulsed Doppler sonography. Gestational age has different effects on OA-BFV and on C-BFV. Although it is a point of discussion if blood flow velocities are reflecting absolute blood flow, Doppler assessment of OA-BFV could be a tool for monitoring risk factors for retinopathy of prematurity. (Pediatr Res 24: 613-616, 1988)
\end{abstract}

\section{Abbreviations}

$\mathrm{CO}$, cardiac output $(\mathrm{ml} / \mathrm{min})$

C-BFV, cerebral blood flow velocity $(\mathrm{cm} / \mathrm{s})$

OA-BFV, ophthalmic artery blood flow velocity $(\mathrm{cm} / \mathrm{s})$ bpm, beats/min

Recent observations indicate that changes in retinal blood flow may be involved in the pathogenesis of retinopathy of prematurity (1-3). Doppler sonography has been introduced and validated as an indirect technique to estimate cerebral blood flow (4). It was the purpose of this study to evaluate if also ophthalmic artery blood flow velocity can be assessed by pulsed Doppler sonography in term and preterm newborn infants and to study the relation of ophthalmic to $\mathrm{C}-\mathrm{BFV}$.

\section{MATERIALS AND METHODS}

A total of 25 neonates was examined during the first week of life, with informed consent of parents and approval by the hospital's ethical committee. All infants were appropriate for gestational age (5) by maternal dates and according to the Ballard

Received April 13, 1988; accepted June 27, 1988. Correspondence W. Lindner, M.D., Department of Pediatrics, University of Munich, Lindwurmstr. 4, D-8000 München 2, Federal Republic of Germany.

${ }^{1}$ Partly presented at the ESPR meeting, Padova 1987 [Pediatr Res 1987, 22:241(abstr)]. score (6). Exclusion criteria were postnatal asphyxia (Apgar at 5 min $<8$ ), congenital heart disease or failure, including patent ductus arteriosus and persistent fetal circulation (excluded by Doppler echocardiographic examination), intracranial hemorrhage, cerebral malformations (excluded by cranial sonography), and maternal diseases such as diabetes or eclampsia. Fifteen healthy term neonates had a gestational age of 40 (37-41) wk (median and range), birth weight of $3360(2550-4040) \mathrm{g}$, heart rate of $130(103-151) \mathrm{bpm}$, and age at examination of $2(1-5)$ days. Perinatal course of these infants was normal. All infants had a normal umbilical artery $\mathrm{pH}(>7.25)$ and hematocrit $(0.44-$ $0.53)$.

The 10 preterm neonates had a gestational age of $29(26-35)$ wk, birth weight of $1100(770-2400) \mathrm{g}$, heart rate of $147(127-$ $171) \mathrm{bpm}$, and age at examination of 2 (1-7) days. All were normotensive and venous hematocrit was $0.46(0.40-0.59)$. Five of these preterm infants were breathing without ventilatory support, one received continuous positive airway pressure $(3-4 \mathrm{~cm}$ $\mathrm{H}_{2} \mathrm{O}$ ), and four were treated with intermittent positive pressure ventilation with peak inspiratory pressures of $15(10-21) \mathrm{cm}$ $\mathrm{H}_{2} \mathrm{O}$, positive endexpiratory pressure of $3 \mathrm{~cm} \mathrm{H} \mathrm{H}_{2} \mathrm{O}$, and $\mathrm{FiO}_{2}$ of $0.25(0.21-0.35)$. All preterm infants were normoxemic with an arterial or transcutaneous $\mathrm{PO}_{2}$ of 52 (45-69) torr and a $\mathrm{PCO}_{2}$ of $38(30-45)$ torr. All infants were in a stable clinical condition, none received inotropic drugs. No sedation was used in the term infants, three preterm infants received phenobarbital (plasma levels $10-40 \mu \mathrm{g} / \mathrm{ml})$. All infants were sleeping or in a quiet state during examination.

Blood flow velocities were measured using a simultaneous twodimensional ultrasound and pulsed Doppler device (Ultramark 8 or Ultramark 4, Squibb Medical Systems, Bellevue, NY), with a 7.5 or $5.0 \mathrm{MHz}$ transducer. The intensities at the transducer surface were $13.5 \mathrm{~mW} / \mathrm{cm}^{2}(5.0 \mathrm{MHz})$ and $15.5 \mathrm{~mW} / \mathrm{cm}^{2}(7.5$ $\mathrm{MHz}$ ). The duty factor was $0.1 \%$. The power of the ultrasound was reduced to $50 \%$ during the imaging of the orbita. The gain for the Doppler was $78 \pm 6 \%$. The Doppler tracings were recorded at $100 \mathrm{~mm} / \mathrm{s}$. Sample volume size was $1.5 \mathrm{~mm}$. A wall filter of $200 \mathrm{~Hz}$ was used. The Doppler spectral data were analysed using the fast Fourier transformation and displayed as flow velocities $(\mathrm{cm} / \mathrm{s})$. Measurements were made from a video tape using the electronic calipers of Ultramark 8 or by hand from the paper recordings of Ultramark 4. Mean BFV over the cardiac cycle was calculated according to the method of Evans (7).

OA-BFV was measured in both eyes. The orbitae were visualized by sagittal scans through the closed eyelids, with the transducer lightly angled from the lateral to the medial wall of the orbita. Dexpanthenol eye ointment (Bepanthen, HoffmannLa Roche AG, Grenzach-Wyhlen, Federal Republic of Germany) was used as contact layer. The transducer was dipped into the eye ointment without direct contact to the bulb. Thus minimal or no pressure was applied to the eye during the examination. In no case did the heart rate decrease during the ultrasound examination of the eye. The bulb, the optical nerve, and the pulsations of the ophthalmic artery can be identified during the two-dimen- 
sional ultrasound examination of the orbita. The sample volume was positioned into the top of the orbital pyramid, when the whole length of the orbita was visualized (Fig. 1). At this position there is no other artery of comparable size that could interfere with the blood flow measurement of the ophthalmic artery. When the blood flow in the ophthalmic artery was detected, minimal transducer movements were made to find a Doppler curve that met the following criteria: a steep systolic acceleration, a sharp peak in systolic blood flow velocity, and a visible incision at the time of aortic valve closure. The Doppler curves were recorded when systolic and diastolic flow velocities were maximal and stable over 10 cardiac cycles (Fig. 2). The mean time that was needed for the examination of OA-BFV was $5 \mathrm{~min}$. This means an exposure time of less than $1 \mathrm{~s}$, considering the duty factor of $0.1 \%$. All examinations and measurements were performed by the same investigator (W.L.). C-BFV was measured in the anterior cerebral artery by a sagittal scan through the fontanel. The sample volume was positioned just below the corpus callosum (8). Criteria for the Doppler tracings of C-BFV were the same as described above. Cardiac output was measured as described by Alverson et al. (9).

Heart rates were derived from the Doppler curves. Blood pressure was monitored indirectly by an oscillometric (Dinamap, Critikon, Florida) or Doppler (Arteriosonde, Roche, Basel, Swit-

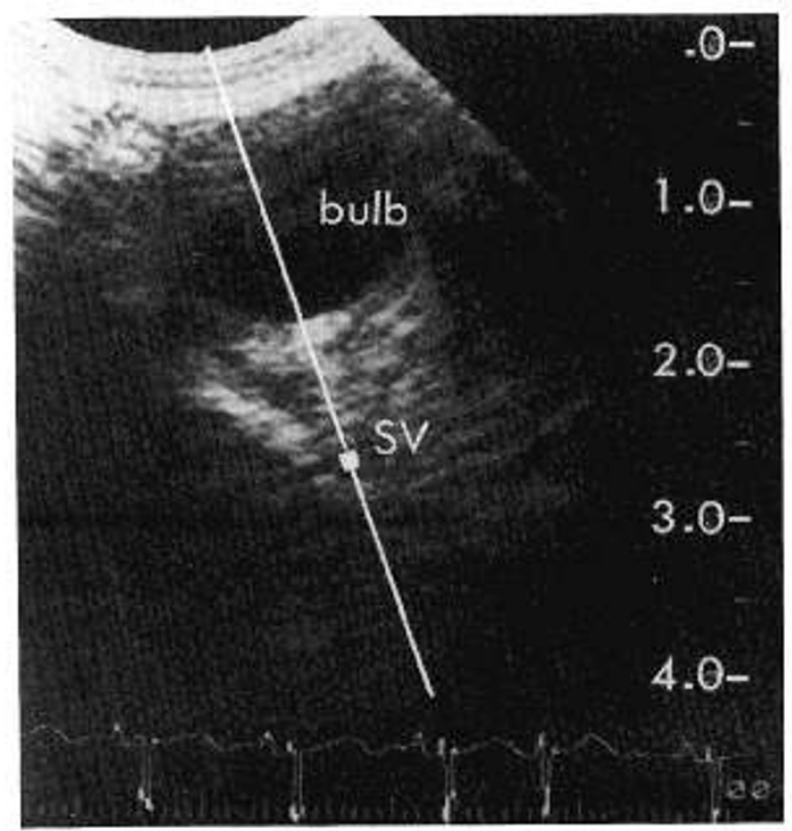

Fig. 1. Sonographic image of the orbita of a preterm neonate $S V$, sample volume.

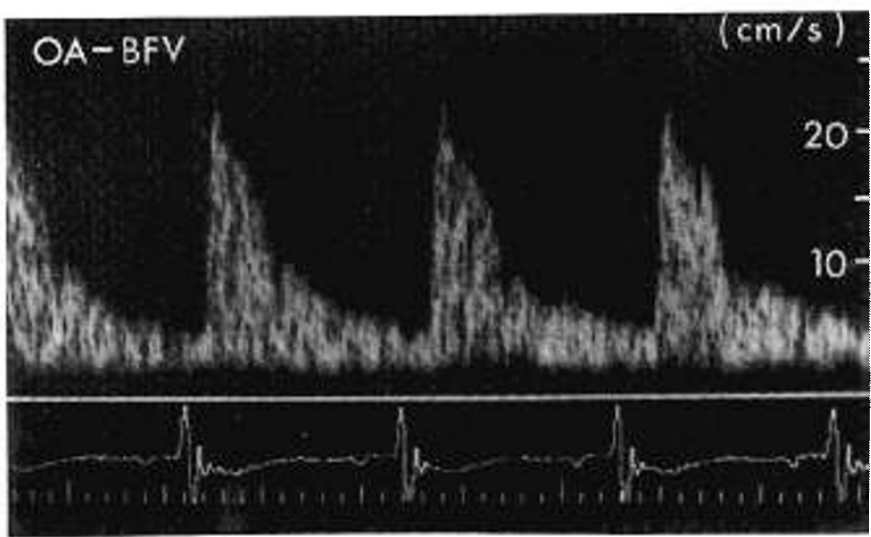

Fig. 2. Doppler tracing of OA-BFV. zerland) device. Transcutaneous blood gases were monitored with combined $\mathrm{PO}_{2}$ and $\mathrm{PCO}_{2}$ electrodes (Kontron, Roche, Basel, or Sensormedics, Anaheim, CA).

Statistical evaluations included group comparisons by the Mann-Whitney test and linear regression analysis. Results were considered statistically significant at $p<0.05$.

\section{RESULTS}

OA-BFV could be obtained in both eyes of all infants examined. The coefficient of intraindividual variation $(n=20)$ was $3.6 \%$. The difference (\% of peak systolic BFV) between right and left OA-BFV, was $10 \pm 8 \%$ (mean $\pm \mathrm{SD}$ ).

The distance of the transducer surface to the sample volume (gate depth) increased with increasing weight: $770-1000 \mathrm{~g}: 2.0 \pm$ $0.14 \mathrm{~cm} ; 1100-1980 \mathrm{~g}: 2.46 \pm 0.16 \mathrm{~cm} ; 2080-2770 \mathrm{~g}: 2.73 \pm$ $0.17 \mathrm{~cm} ; 3100-4040 \mathrm{~g}: 3.35 \pm 0.17 \mathrm{~cm}$.

Data on OA-BFV, C-BFV, and CO are given in Table 1. Peak systolic, mean, and end diastolic $\mathrm{OA}-\mathrm{BFV}$ were not different in term and preterm infants (Fig. 3; Table 1), but C-BFV increased significantly with increasing gestational age (peak systolic ACA$\mathrm{BFV}=1.04 \times$ gestational age $+1.6, r=0.58, p<0.01$; mean $\mathrm{ACA}-\mathrm{BFV}=0.33 \times$ gestational age $-0.8, r=0.65, p<0.01$; end diastolic ACA-BFV $=0.48 \times$ gestational age $-4.7, r=0.61$, $p<0.01$ ) (Table 1). A significant positive correlation of peak systolic and mean OA-BFV versus peak systolic and mean C$\mathrm{BFV}$ was seen in preterm (peak systolic $\mathrm{OA}-\mathrm{BFV}=0.63 \times$ peak systolic C-BFV $+8.2 ; r=0.88, p<0.001$ (Fig. 4); mean OA$\mathrm{BFV}=0.43 \times$ mean $\mathrm{C}-\mathrm{BFV}+3.1 ; r=0.63, p<0.01$ ), but not in term neonates. The ratio OA-BFV/C-BFV (peak systolic BFV) was $0.89 \pm 0.11$ in preterm and $0.68 \pm 0.24$ in term infants $(p$ $<0.01)$ and the ratio mean $\mathrm{OA}-\mathrm{BFV} /$ mean $\mathrm{C}-\mathrm{BFV}$ was $0.79 \pm$ 0.17 in preterm and $0.56 \pm 0.14$ in term infants, respectively $(p$ $<0.01$ ).

Heart rate was $150 \pm 13(\mathrm{SD}) \mathrm{bpm}$ in preterm and $131 \pm 14$ $\mathrm{bpm}$ in term infants. Heart rate variation during individual examinations was $14 \pm 6 \mathrm{bpm}$ in preterm and $16 \pm 6 \mathrm{bpm}$ in term infants. In the five ventilated preterm infants (gestational age $28 \pm 2 \mathrm{wk}$ ) heart rate was $156 \pm 12 \mathrm{bpm}$, and $143 \pm 11 \mathrm{bpm}$ in the five more mature nonventilated preterm infants (gestational age $32 \pm 2 \mathrm{wk}$ ). Differences of arterial or transcutaneous $\mathrm{PO}_{2}$ and $\mathrm{PCO}_{2}$ and venous hematocrit in the ventilated and nonventilated preterm infants were not statistically significant. Peak systolic OA-BFV was $27 \pm 3 \mathrm{~cm} / \mathrm{s}$ in ventilated and $32 \pm 6$ in nonventilated preterm infants (NS).

\section{DISCUSSION}

To our knowledge this is the first report on ophthalmic artery blood flow velocity. An important issue, and therefore discussed first, is the question if the ultrasound examination of the eye is safe or not. This method has been used by ophthalmologists for more than 25 yr without any observed side effects (10). In animal

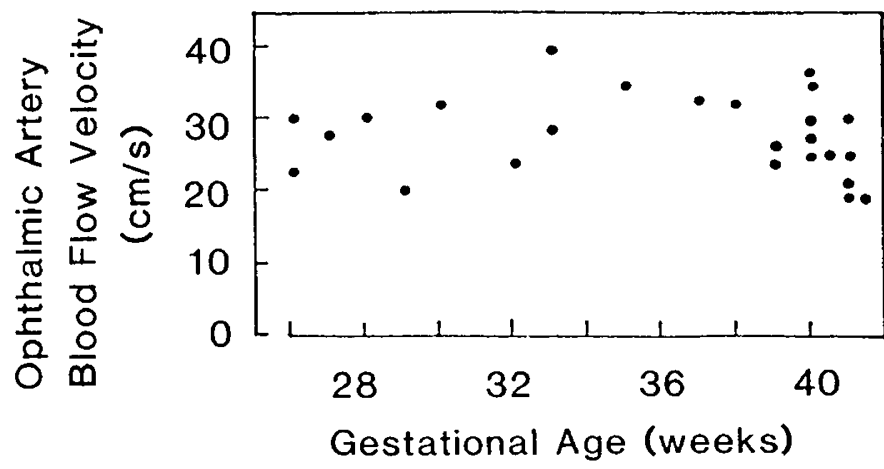

Fig. 3. Ophthalmic artery peak systolic blood flow velocity $(\mathrm{cm} / \mathrm{s})$ plotted against gestational age. Linear regression, NS. 
Table 1. Ophthalmic and C-BFV and cardiac output in term and preterm neonates in Ist wk of life (mean $\pm S D)$

\begin{tabular}{|c|c|c|c|c|}
\hline & & $\begin{array}{c}\text { Preterm } 26-35 \text { wk } \\
\quad(n=10)\end{array}$ & $\begin{array}{c}\text { Term } 37-41 \text { wk } \\
\quad(n=15)\end{array}$ & $p$ \\
\hline Ophthalmic artery & (Peak systolic) & $29.0 \pm 5.0$ & $27.0 \pm 5.0$ & NS \\
\hline \multirow[t]{2}{*}{$\mathrm{BFV}(\mathrm{cm} / \mathrm{s})$} & (Mean) & $7.2 \pm 1.5$ & $6.6 \pm 1.3$ & NS \\
\hline & (End diastolic) & $6.1 \pm 1.4$ & $6.1 \pm 1.6$ & NS \\
\hline Anterior cerebral art. & (Peak systemic) & $34.0 \pm 8.0$ & $43.0 \pm 9.0$ & $<0.05$ \\
\hline \multirow[t]{2}{*}{$\mathrm{BFV}(\mathrm{cm} / \mathrm{s})$} & (Mean) & $9.4 \pm 2.3$ & $11.0 \pm 3.0$ & $<0.05$ \\
\hline & (End diastolic) & $9.5 \pm 2.6$ & $14.3 \pm 4.2$ & $<0.01$ \\
\hline Cardiac output (ml/min) & & $329 \pm 128$ & $732 \pm 112$ & $<0.001$ \\
\hline Cardiac output $(\mathrm{ml} / \mathrm{min} / \mathrm{kg}$ ) & & $259 \pm 13$ & $215 \pm 15$ & $<0.01$ \\
\hline
\end{tabular}
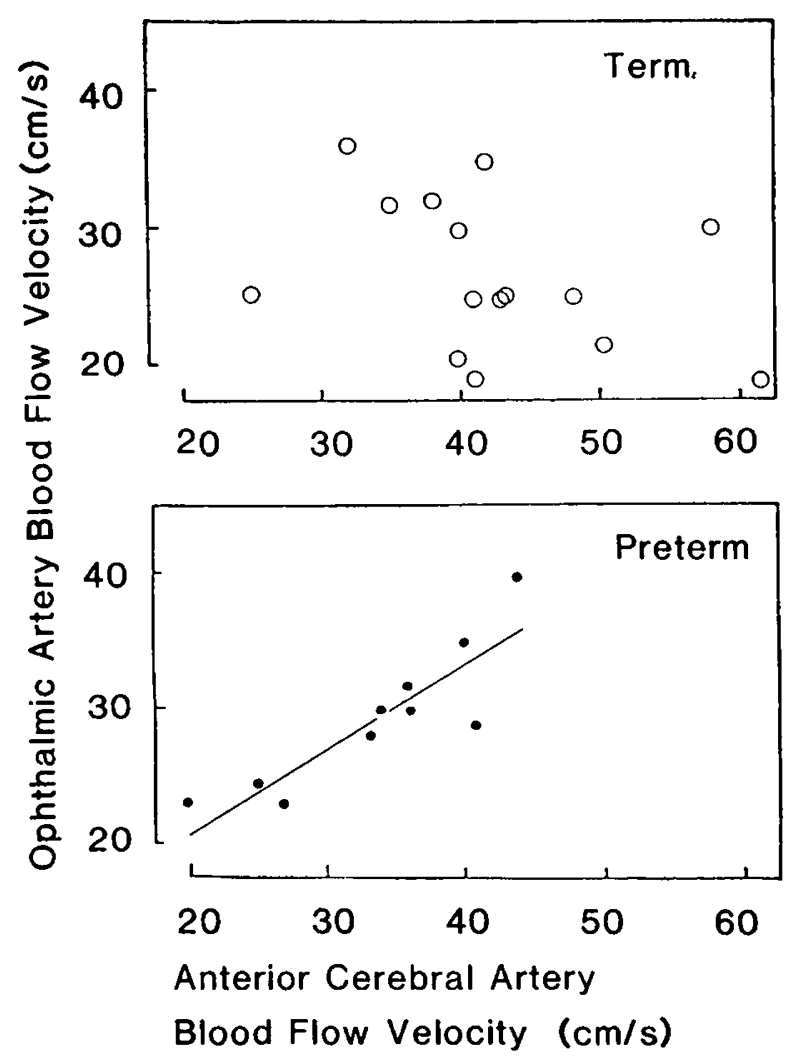

Fig. 4. Peak systolic ophthalmic artery blood flow velocity plotted against peak systolic cerebral blood flow velocity in term $(O)$ and preterm $(\bullet)$ neonates. Linear regression: term: NS; Preterm: OA-BFV $=0.63 \times$ $\mathrm{ACA}-\mathrm{BFV}+8.2 ; r=0.88 ; p<0.001$.

studies, eyes were exposed to diagnostic ultrasound intensities for several hours and no pathologic changes could be found (11). Damage of ocular tissues was produced in animals only by high intensity ultrasound that far exceeds the diagnostic intensities we used in our study (factor $2.2 \times 10^{4}$ at an ultrasound exposure time of 1 s) (10). The fetal and neonatal eye is exposed to ultrasound energy during obstetric and cranial sonography, but until now no adverse effects of diagnostic ultrasound are known (12). The duration of ultrasound exposure for the Doppler examination of the ophthalmic artery was less than $1 \mathrm{~s}$, and the power of the instrument was reduced to $50 \%$ to minimize the ultrasound energy. For these reasons we consider Doppler examination of the ophthalmic artery to be a method, which may be used in neonates.

With the combined two-dimensional and pulsed Doppler technique, we were able to measure ophthalmic artery blood flow velocity in term and preterm infants. The examination through the closed eyelid was well tolerated by the infants. This approach provides an ultrasound beam that is nearly coaxial to the ophthalmic artery, a condition required for an optimal Doppler tracing.
The cardiac output and cerebral blood flow velocities observed in this study agree well with literature data on normal neonates $(9,13)$. Our data on mean cerebral blood flow velocity (anterior cerebral artery) are slightly higher than those reported by Evans et al. (8) and by Drayton and Skidmore (14). These differences are expected, because Evans et al. (8) studied neonates less than $1500 \mathrm{~g}$ and Drayton and Skidmore (14) studied infants up to the age of $48 \mathrm{~h}$, whereas our preterm infants had a weight up to 2400 $\mathrm{g}$ and an age up to 7 days, and cerebral blood flow velocity is known to increase with gestational age and with postnatal age $(8,14)$. Evans et al. (8) and Drayton and Skidmore (14) did not report on other variables influencing cerebral blood flow velocity like Apgar scores, hematocrit, mechanical ventilation, or $\mathrm{pCO}_{2}$.

Considering the normal cardiac output and cerebral blood flow velocities, and the exclusion criteria, the ophthalmic artery blood flow velocities of our infants should have been normal. Ophthalmic artery blood flow velocities were the same in term and preterm infants. This is in contrast to the observation that cerebral blood flow velocities increase with increasing gestational age $(13,14)$. Thus the ratio of ophthalmic artery blood flow velocity over cerebral blood flow velocity was significantly higher in preterm infants. Peak systolic, mean, and end diastolic cerebral blood flow velocities are directly related to absolute cerebral blood flow $(15,16)$. It is unknown if this relation is also true for ophthalmic blood flow velocities and absolute ophthalmic blood flow in normal neonates. Blood flow velocities depend not only on absolute blood flow but also on various factors such as arterial blood pressure, whole blood viscosity, vessel diameters, and vascular resistances. Information on these physiologic variables and their changes with increasing gestational age is lacking in neonates. Thus a discussion about changes of absolute ophthalmic or cerebral blood flow with increasing gestational age from our data would be speculative.

Another interesting result of our study is the positive correlation of ophthalmic artery blood flow velocity to cerebral blood flow velocity $(r=0.88$, peak systolic BFV; $r=0.63$ mean BFV) in preterm but not in term neonates. The discussion of this different relationship is difficult again, because of the lack of additional physiologic data, which are not obtainable in infants by noninvasive techniques. Stiris et al. (17), investigating ocular and cerebral blood flow by a microsphere method in an animal model, assume a separate regulation of ocular blood flow. We did not study intraindividual changes of ophthalmic and cerebral blood flow velocities, and absolute ophthalmic blood flow cannot be derived from the Doppler measurement of ophthalmic blood flow velocity, because noninvasive measurement of the ophthalmic vessel diameters is not possible with current techniques. Thus we cannot substantiate this hypothesis in human neonates.

Retinopathy of prematurity is still a major problem in preterm infants. At the present time Doppler assessment of the ophthalmic blood flow velocity is the closest noninvasive approach to the retinal circulation in neonates, but further studies are required to evaluate the relation of ophthalmic artery blood flow velocity to retinal blood flow and retinopathy of prematurity. 
Acknowledgments. The authors thank Monika Güntner for assistance with the figures. The help of our nurses during the study is gratefully acknowledged.

\section{REFERENCES}

1. Lucey JF, Dangman B 1984 A reexamination of the role of oxygen in retrolental fibroplasia. Pediatrics 73:82-96

2. Flower RW, Blake DA 1981 Retrolental fibroplasia: evidence for a role of the prostaglandin cascade in the pathogenesis of oxygen-induced retinopathy in the newborn beagle. Pediatr Res 15:1293-1302

3. Flower RW 1981 A new perspective on the pathogenesis of retrolental fibroplasia: the influence of elevated arterial $\mathrm{PCO}_{2}$. Proceedings of the Ross Conference on retrolental fibroplasia. Ross Laboratories, Columbus, $\mathrm{OH}$ vol 1, p 20

4. Volpe JJ 1987 Cerebral blood velocity monitoring. In: Volpe JJ (ed) Neurology of the Newborn, 2nd ed. WB Saunders Co, Philadelphia, pp 114-117

5. Usher R, McLean F 1969 Intrauterine growth of live-born Caucasian infants at sea level: standards obtained from measurements in 7 dimensions of infants born between 25 and 44 weeks of gestation. J Pediatr 74:901-910

6. Ballard JL, Kazmaier K, Driver M 1977 A simplified score of fetal maturation of newly born infants. J Pediatr 95:769-774

7. Evans DH 1985 On the measurement of the mean velocity of blood flow over the cardiac cycle using Doppler ultrasound. Ultrasound Med Biol 11:735741

8. Evans DH, Levene MI, Shortland DB, Archer LNJ 1988 Resistance index, blood flow velocity, and resistance-area product in the cerebral arteries of very low birth weight infants during the first week of life. Ultrasound Med Biol 14: 103-110

9. Alverson DC, Eldridge M, Dillon T, et al 1982 Noninvasive pulsed Doppler determination of cardiac output in neonates and children. J Pediatr 101:4650

10. Coleman DJ, Lizzi FL, Jack RL 1977 Biological effects of high intensity ultrasound. In: Coleman DJ (ed) Ultrasound of the Eye and Orbit. Lea and Febiger, Philadelphia, pp 42-49

11. Ziskin M, Romayandanda N, Harris K 1974 Ophthalmologic effect of ultrasound at diagnostic intensities. J Clin Ultrasound 2:119-122

12. National council on radiation protection and measurements 1983 Protection in Nuclear Medicine and Ultrasound Diagnostic Procedures in Children. Bethesda, MD, NCRP report ISSN 0083-209x; no. 73, issued Dec 30, pp $29-30$

13. Jorch G, Pfannschmidt J, Rabe H 1986 Die nichtinvasive Untersuchung der intracerebralen Zirkulation bei Früh- und Neubegorenen mit der gepulsten Dopplersonographie. Monatsschr Kinderheilkd 134:804-807

14. Drayton MR, Skidmore R 1987 Vasoactivity of the major intracranial arteries in newborn infants. Arch Dis Child 62:236-240

15. Hansen NB, Stonestreet BS, Rosenkrantz TS, Oh W 1983 Validity of Doppler measurements of anterior cerebral blood flow velocity: correlation with brain blood flow in piglets. Pediatrics 72:526-531

16. Batton DG, Hellmann J, Hernandez MJ, Maisels MJ 1983 Regional cerebral blood flow, blood flow velocity and pulsatile index in newborn dogs. Pediatr Res 17:908-912

17. Stiris T, Hansen TWR, Hall K, Bratlid D 1987 Ocular and cerebral blood flow response to variation in arterial $\mathrm{PCO}_{2}$ levels. Pediatr Res 22:142A 